\title{
Reduction in Pseudomonas aeruginosa sputum density during a cystic fibrosis pulmonary exacerbation does not predict clinical response
}

\author{
John C Lam', Ranjani Somayaji ${ }^{1}$, Michael G Surette ${ }^{2,3}$, Harvey R Rabin ${ }^{1,3}$ and Michael D Parkins ${ }^{1,3^{*}}$
}

\begin{abstract}
Background: Pulmonary exacerbations (PEx) are critical events in cystic fibrosis (CF), responsible for reduced quality of life and permanent loss of lung function. Approximately 1/4 of PEx are associated with failure to recover lung function and/or resolve symptoms. Developing tools to optimize PEx treatment is of paramount importance.

Methods: We retrospectively audited all adults infected with Pseudomonas aeruginosa, experiencing PEx necessitating parenteral antibiotic therapy from 2006-2012 from our center. Quantitative analysis of sputum at admission, twice-weekly during hospitalization, and end of therapy were compared to baseline (most recent healthy) and follow-up (after PEx) samples. Change in P. aeruginosa burden from baseline was assessed for any and all morphotypes (ALL), as well as mucoid (MUC) and non-mucoid (NON) isolates specifically. PEx were identified as failures if $>90 \%$ of baseline pulmonary function was not recovered.
\end{abstract}

Results: Forty-six patients meeting the above inclusion and exclusion criteria experienced 144 PEx during this time (median 3, IQR 2-6). Patients were treated for a median 14 days (IQR 13-16). No increase in ALL, MUC or NON were detected at PEx, nor was there an association between change in sputum density and magnitude of lung function decline. PEx failures were observed in 30\% of events. Reductions of at least 1-log and 2 log P. aeruginosa sputum density was observed in 57\% and 46\% (ALL), 73\% and 55\% (MUC) and 58\% and 46\% (NON) of PEx, respectively. Factors associated with greater reduction of $\mathrm{P}$. aeruginosa sputum density included choice of $\beta$-lactam antibiotic, antibiotics with in vitro predicted activity and treatment duration. PEx associated with reductions in P. aeruginosa sputum density were not associated with a reduced risk of PEx failure.

Conclusions: Enhanced killing of P. aeruginosa during PEx does not predict improved clinical outcomes. Studies accounting for the polymicrobial nature of CF respiratory disease and the heterogeneity of P. aeruginosa causing chronic infection may enable the identification of a more appropriate pathogen(s) based biomarker of PEx outcomes.

Keywords: Treatment, Biomarker, Failure, Outcome, Bronchiectasis, Cefepime, Heterogeneity

\section{Background}

The archetypal CF pathogen, Pseudomonas aeruginosa infects $50-70 \%$ of patients [1]. Patients with chronic $P$. aeruginosa infection have increased rates of lung function decline, health care utilization, and reduced survival [2-4]. Chronic $P$. aeruginosa infection is punctuated by frequent

\footnotetext{
* Correspondence: mdparkin@ucalgary.ca

'Department of Medicine, The University of Calgary, 3330 Hospital Dr. NW, Calgary, Alberta T2N 4 N1, Canada

${ }^{3}$ The Department of Microbiology, Immunology and Infectious Disease, The University of Calgary, Calgary, Canada

Full list of author information is available at the end of the article
}

acute deteriorations termed pulmonary exacerbations (PEx). PEx are characterized by increased cough and sputum production, disproportionate shortness of breath and loss of lung function, as well as increased inflammation [5-7]. PEx are critical events in CF, associated with reduced quality of life [8], increased cost [9], permanent lung damage $[10,11]$ and increased short-term mortality $[12,13]$. So important are these events, they may now constitute primary end-points in CF therapeutic trials [14].

Treatment of PEx usually consists of aggressive airway clearance, respite, nutritional support, and antimicrobial 
therapy directed against chronically infecting pathogens. Despite therapy, 25\% of PEx fail to achieve successful outcomes as determined by lung function recovery, resolution of symptoms and preventing recurrences [15]. Patients more likely to experience unsuccessful PEx outcomes are infected with MRSA, Burkholderia cepacia complex, MDR (multi-drug resistant) $P$. aeruginosa, and those with CF-related diabetes and/or CF-liver disease $[10,15]$. Furthermore, more severe PEx including those with greater initial lung function decline, and those with greater inflammation at initiation and completion of treatment are associated with worse outcomes.

Developing tools to predict PEx outcomes is key to their successful management. It has been previously determined that antibiogram directed therapy against a limited number of isolates of $P$. aeruginosa has only a weak association with PEx outcomes [15]. As such, other biomarkers are increasingly being evaluated for their ability to predict treatment responses. A number of host specific factors are being assessed [16,17]. However, given the critical intervention in PEx is anti-bacterial, the use of bacterial derived biomarkers to follow treatment response deserves attention. While antibacterials have been shown to reduce the bacterial load during the treatment of PEx, how this correlates with clinical response has not been established [18]. Herein we evaluate the use of semi-quantitative reporting of $P$. aeruginosa sputum density and correlated the response with clinical outcomes during PEx treatment.

\section{Methods}

All CF patients chronically infected with $P$. aeruginosa attending the Calgary Adult CF Clinic from 2006-2012 experiencing PEx treated with parenteral antibiotics were considered for inclusion if they had semi-quantitative sputum cultures performed $\geq 3$ times during treatment (baseline, initiation, early, end of therapy) and at followup. Parenteral antibiotics provided for reasons other than PEx were excluded. Patients were excluded if they had a baseline $\mathrm{FEV}_{1}<30 \%$ predicted, were infected with Burkholderia cenocepacia or Mycobacterium abscessus, or were listed for lung transplantation. Detailed review of clinical records were performed from prior to the PEx, through treatment and in follow-up. Pulmonary function was evaluated by spirometry. Data was prospectively collected and retrospectively analyzed. Patients provide prospective consent for studies correlating clinical outcomes with lower airways infection. This project has been approved by the Conjoint Health Research Ethics Board of the University of Calgary (E23087).

\section{Definitions}

Baseline lung function was defined as the best forced expiratory volume in one second $\left(\mathrm{FEV}_{1}\right)$ percent predicted in the preceding 6 months. The Leeds criteria was used to define chronic P. aeruginosa infection [19]. PEx were diagnosed on clinical grounds in real time, however, charts were evaluated and scored according to Fuchs criteria retrospectively [5]. Parenteral therapies were provided as either an inpatient, outpatient via the home parenteral therapy program (HPTP) or a combination thereof. Treatment failures were defined a priori as failure to have recovered $90 \%$ of baseline $\mathrm{FEV}_{1}$ at follow-up (FTR90) $[10,11,15]$. Severity of lung disease was categorized as mild ( $\mathrm{FEV}_{1} \%$ predicted $\left.\geq 70 \%\right)$, moderate $(40-70 \%)$, and severe $(<40 \%)$. Bacterial sputum density is reported as $\log 10 \mathrm{CFU} / \mathrm{ml}$. Bacteriologic responses to antipseudomonal therapies were evaluated as either a one or two-log drop in CFU/ml.

\section{Antibacterial therapies}

Anti-Pseudomonal $\beta$-lactams (aztreonam, ceftazidime, cefepime, and meropenem) were dosed 2 g every 8 hours infused over thirty minutes, ciprofloxacin as $600 \mathrm{mg} I V$ or $750 \mathrm{mg}$ PO every 12 hours, and tobramycin as $10 \mathrm{mg} / \mathrm{kg} /$ day divided in 1-2 doses. When patients with chronic Staphylococcus aureus co-infection were treated with regimens lacking Staphylococcal activity such as aztreonam/ceftazidime, supplemental anti-Staphylococcal therapies were used and consisted of trimethoprim/ sulfamethoxazole (TMP/SMX) 320/1600 mg PO BID, linezolid $600 \mathrm{mg}$ PO BID, rifampin $300 \mathrm{mg}$ PO BID, or cloxacillin $2 \mathrm{~g}$ IV q4h, clindamycin $600 \mathrm{mg}$ IV q8h, ceftriaxone $2 \mathrm{~g}$ IV q12h or tigecycline $50 \mathrm{mg}$ q12h.

\section{Microbiologic investigations}

Baseline sputum samples were from the most recent clinic where patients were not experiencing PEx. Twiceweekly sputum samples were collected through treatment. Admission samples were collected before starting therapy. Changes in bacterial load were evaluated at "EARLY" ( $3^{+/} 2$ days from starting) and "END" (within 3 days of completion). Follow-up samples were collected at the next clinic visit attended.

Sputum samples were mixed with equal volumes of dithiothreitol (DTT, Sputolysin, EMD Millipore, MA) and vortexed. Samples were serial diluted in DTT to $10^{-5}$ and plated on Columbia Blood Agar (CBA), MacConkey Agar, (MAC), Chocolate Agar (CHOC), Burkholderia cepacia selective agar, and Mannitol Salt Agar. Pathogens were identified by standard criteria [20]. Oral flora (OF) included organisms such as non-hemolytic Streptococci, Haemophilus parainfluenzae, Corynebacterium spp., Neisseria spp. (non-meningitidis) and Coagulase-negative Staphylococci grown on CBA or CHOC. Organisms were quantified and $P$. aeruginosa colonies classified as mucoid (MUC) or non-mucoid (NON) isolates based on growth on MAC [21]. P. aeruginosa susceptibility testing was 
performed on each morphotype by Kirby-Bauer or E-test as per CLSI guidelines [22]. Where $>1 \mathrm{MUC} / \mathrm{NON}$ isolates existed susceptibility testing was performed on each, and the result represents the least susceptible. MDR was defined as resistance to all antibiotics in $\geq 2$ classes and pan-drug resistance (PDR) all classes, save for colistin [15,23].

\section{Statistical analysis}

Means with standard deviation (SD) or medians with inter-quartile ranges (IQR) were used to describe normal and non-normally distributed data, respectively. Categorical variables were compared using a two-sided Fisher's exact test. Odds ratios (OR) were calculated by dividing the proportion with a factor to those without and were reported with $95 \%$ confidence intervals (CI). Continuous variables were compared using Pearsons correlation coefficient. Statistical analyses were performed using Stata 12.0 (Stata Corp., College Station, TX, USA). A p value of $\leq 0.05$ was considered significant.

\section{Results}

\section{Patients and PEx}

Of a total eligible cohort of 176, 46 patients met inclusion criteria. These 46 patients experienced $144 \mathrm{PEx}$ during the six-year study period. Median age of those included was 32.9 years (IQR 27.9-40). Patients were diagnosed with CF at a median age of 1.35 years (IQR 0.5-6). $56 \%$ were F508del homozygous and $83 \%$ carried $\geq 1$ allele. 43 patients (93\%) were pancreatic insufficient. Co-morbidities included CF-related diabetes in 18 (40\%), CF-liver disease 8 (18\%), osteopenia $60 \%$ and osteoporosis $9 \%$. During the six years of study, 14 patients initially included had future events excluded because of progression of disease and three patients died, although none from CF.

Patients experienced a median 3 exacerbations (IQR 2-6). Time to next PEx was 207 days (IQR 93-458). Complete details were not available for all. Using Fuchs criteria to confirm the clinical diagnosis of PEx, patients had a median of 5 criteria (IQR 5-7), where 4 meet the definition. The most common criteria were increased cough (99\%) and sputum (99\%), increased dyspnea (98\%), decreased $\mathrm{FEV}_{1}$ by $\geq 10 \%$ (94\%), weight loss or anorexia (77\%), change in chest exam (72\%), radiographic infiltrates (52\%), lethargy (46\%), fevers (37\%), and hemoptysis (36\%). Sinus/nasal discharge symptoms were uncommonly documented (2\%). At the time of exacerbation, chronic medications included: azithromycin 56\%, H2-blockers or protonpump inhibitors $37 \%$, inhaled corticosteroids (ICS) $54 \%$, long acting bronchodilators $85 \%$, nebulized DNase $66 \%$, tobramycin inhalation solution $54 \%$, and aztreonam solution for inhalation $4 \%$. With the exception of inhaled antibiotics, chronic medications were continued during PEx. 70 (48\%) of events were exclusively managed in hospital, $42(29 \%)$ were treated with HPTP, $32(22 \%)$ started off in hospital but completed at home, and two (1\%) were admitted to hospital from HPTP. Exacerbations were associated with a median 19.3\% (IRQ 11-28.5) and 18.2\% (9.9-29) drop in $\mathrm{FEV}_{1}$ and $\mathrm{FVC}$ respectively.

Patients were treated for a median 14 days (IQR 13-16). Two anti-pseudomonal antibiotics were used in $98 \%$ of exacerbations, and three in $2 \%$. These generally consisted of an anti-pseudomonal $\beta$-lactam and tobramycin (96\%). Ceftazidime was used in 51\%, meropenem 24\%, cefepime $16 \%$, and aztreonam $7 \%$. Rarely ciprofloxacin was combined with tobramycin (2\%). Tobramycin was used in once $(14 \%)$ or twice-daily doses (81\%), and parenteral ciprofloxacin was used in place of tobramycin in five (3\%) exacerbations. Additional anti-Staphylococcal therapy was used in 37 (26\%) PEx and consisted of TMP/SMX (38\%), cloxacillin and TMP/SMX (19\%), cloxacillin and rifampin (14\%), cloxacillin (11\%) and rifampin, clindamycin, clindamycin and ceftriaxone, tigecycline and linezolid each in $3 \%$.

Patients presented with an exacerbation 68 days (IQR 32-111) after their most recent clinic visit. Mean duration from initiation of antibiotics to collection of EARLY sputum culture was 3.84 days (SD 1.75). Mean duration from the end of therapy to collection of END sputum sample was 0.72 days (SD 1.70). 40 days (IQR 27-61) after completion of PEx treatment, patients were seen in follow-up at a regular CF clinic.

\section{PEx outcomes}

PEx treatment failures, as defined by failing to recover $90 \%$ of baseline $\mathrm{FEV}_{1}$, were observed in 42/140 (30\%). Neither sign, symptom, nor total Fuchs' initial PEx diagnostic score were associated with increased failure risk (not shown). Stage of CF-lung disease did not influence failure (not shown). Antibiotic courses $\leq 10$ days were more likely to be deemed failures; 8/16 (50\%) vs 38/128 (30\%), OR 1.68 (0.972.94), $\mathrm{p}=0.15$ ) but this did not reach statistical significance. Few prior and concomitant medications influenced PEx outcomes. In particular, prior tobramycin inhalation solution was associated with a trend to reduced risk of failure [17/74 vs $24 / 63$ OR 0.6 (CI $0.36-1.01$ ), $\mathrm{p}=0.06$ ] whereas concomitant ICS were associated with a trend to increased risk [27/42 vs 47/97, OR 1.33 (CI 0.98-1.80), $\mathrm{p}=0.09$ ] of failure. Antibiotic choice did not impact PEx outcome, nor did the number of antibiotics with in vitro predicted activity against ALL, MUC or NON (not shown). Failure risk did not differ based on delivery of PEx treatment; 33/68 (49\%) in hospital, 18/42 (43\%) HPTP, 9/32 (28\%) transitioned from hospital to HPTP, 1/2 (50\%) admitted to hospital from HPTP, $\mathrm{p}=0.24$. Concurrent use of additional anti-staphylococcal agents did not reduce failure risk [11/30 (36\%) vs 31/110 (28\%), OR 1.32 (CI 0.75-2.31), $\mathrm{p}=0.37$ ]. 


\section{Bacteriologic response to antibiotics during PEx}

Median sputum density of OF at PEx was $10^{6} \mathrm{CFU} / \mathrm{ml}$ (IQR $10^{5}-10^{6}$ ), S. aureus $10^{6}$ (IQR $10^{5}-10^{6}$ ), P. aeruginosa ALL $10^{6}$ (IQR $10^{6}-10^{7}$ ), MUC $10^{6}$ (IQR $10^{5}-10^{6}$ ) and NON $10^{6}$ (IQR $10^{5}-10^{7}$ ). Relative to baseline, admission PEx samples did not demonstrate an increase in $P$. aeruginosa burden (Figure 1A). Furthermore, there was no correlation between the extent of pulmonary function decline at PEx presentation and change in bacterial load (not shown). Treatment produced a progressive decline in $P$. aeruginosa in $60 \%$ of patients peaking at end of therapy, but returned to baseline at follow-up (Figure 1B-D). Stage of lung disease during PEx did not influence bacteriologic response (not shown).

Clinical outcomes were not predicted based on changes in sputum bacterial burden at completion of PEx treatment (Table 1). Furthermore, outcomes were not different in those few individuals who transiently cleared ALL, MUC or NON (not shown).

In PEx where anti-pseudomonal $\beta$-lactams were used, $22.5 \%(32 / 142)$ of PEx had $\geq 1$ isolate that was resistant. At least one isolate was resistant to tobramycin, in $54.3 \%$ (77/142) of PEx. Highly resistant isolates were rare in admission PEx samples and over a one-year period prior to PEx (MDR; MUC 6\% (6/103), 22\% (25/116); NON 41\% (45/110), 50\% (57/113) and PDR; MUC 1\% (1/103),
$3 \%$ (3/115) and NON 12\% (13/109), 22\% (25/113), respectively. Antibiotic choice impacted $P$. aeruginosa sputum reduction to varying degrees (Table 2, Figures 2 and 3). Relative to other antibiotics ceftazidime showed a modest advantage, whereas cefepime was associated with reduced $P$. aeruginosa killing. Tobramycin dosing once or twice daily did not influence bacteriologic response (data not shown). An association between number of antibiotics with in vitro predicted activity and reduction of $P$. aeruginosa density was observed although this reached statistical significance only for regimens with activity against the NON-isolates (Table 3 ).

No significant impact of concurrent therapies was noted on reductions in $P$. aeruginosa sputum density. In particular, concurrent chronic azithromycin, DNase, nor hypertonic saline impacted $P$. aeruginosa density. A trend was observed in individuals receiving concurrent ICS at having a lower likelihood of reducing $P$. aeruginosa sputum burden (not shown). Venue for antibiotic delivery did not impact bacteriologic response (not shown). Treatments <14 days produced an inferior bacteriologic response, although this met statistical significance for only the NON-isolates (Table 2).

MSSA was a chronic colonizer of patients in 31/146 (21.2\%) of PEx, and two had a history of recent-prior MRSA transient colonization, though none on admission.
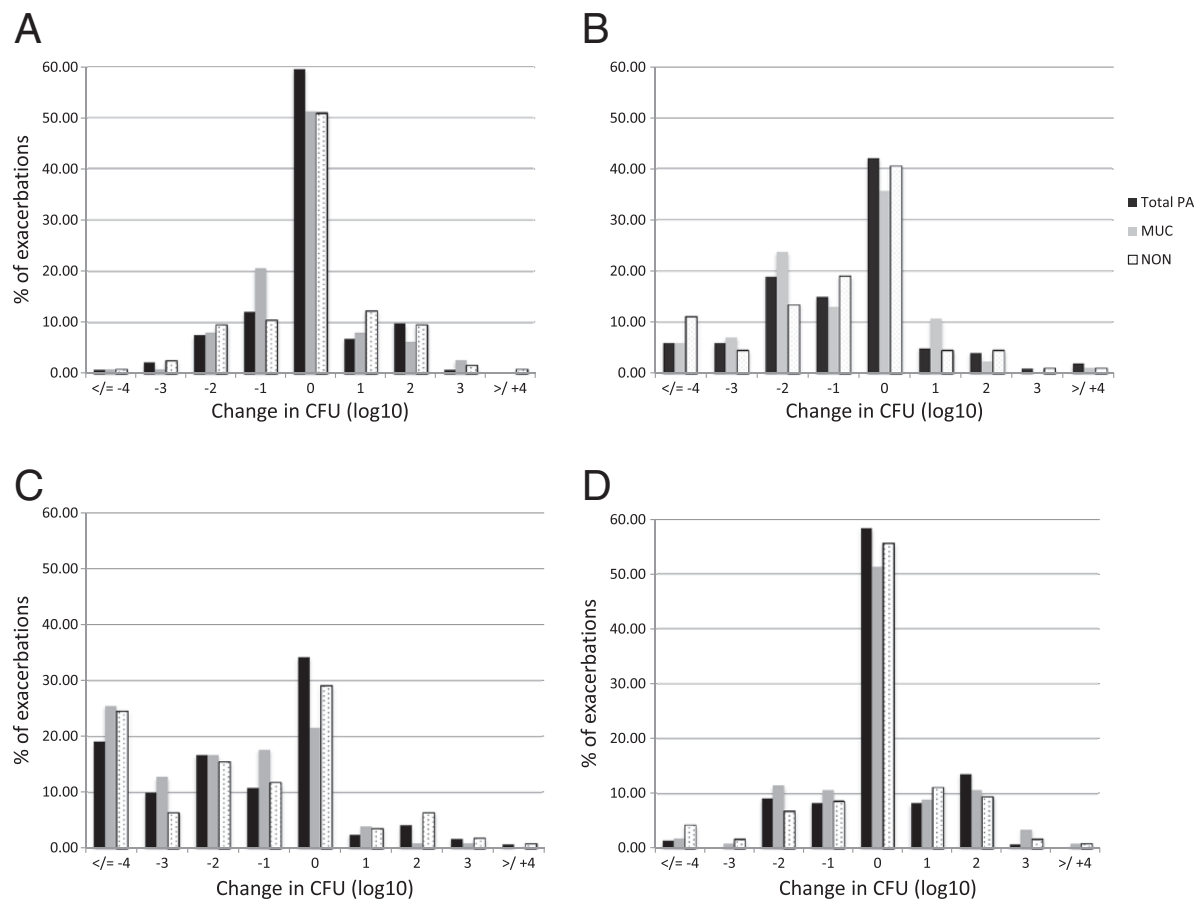

Figure 1 Change in P. aeruginosa CFU/ml during PEx. A). Change in CFU from baseline sputum to admission at time of PEx. B). Change in CFU at EARLY time point ( day 4) of antibiotic treatment relative to admission. C). Change in CFU at the END of antibiotic treatment for PEx relative to admission. D). Change in CFU at follow-up clinic visit relative to admission. Black bars represent all P. aeruginosa isolates, grey bars only MUC, and white bars with black dots NON. 
Table 1 Bacteriologic response does not predict clinical outcomes of pulmonary exacerbations

\begin{tabular}{|c|c|c|c|c|c|}
\hline \multirow[t]{2}{*}{ Organism } & \multirow[t]{2}{*}{ Morph } & \multirow[t]{2}{*}{ Log drop } & \multicolumn{3}{|l|}{ Failure risk* } \\
\hline & & & Actual values** & OR (Cl) & $P$ value \\
\hline \multirow[t]{6}{*}{ P. aeruginosa } & \multirow[t]{2}{*}{$\mathrm{ALL}$} & 1 & $26 \%(18 / 68)$ vs $33 \%(17 / 51)$ & $0.78(0.46-1.38)$ & 0.42 \\
\hline & & 2 & $27 \%(15 / 55)$ vs $31 \%(20 / 64)$ & $0.87(0.5-1.5)$ & 0.68 \\
\hline & \multirow[t]{2}{*}{ MUC } & 1 & $28 \%(21 / 74)$ vs $23 \%(6 / 26)$ & $1.22(0.56-2.70)$ & 0.79 \\
\hline & & 2 & $30 \%(17 / 56)$ vs $22 \%(10 / 44)$ & $1.36(0.68-2.62)$ & 0.49 \\
\hline & \multirow[t]{2}{*}{ NON } & 1 & $30 \%(19 / 64)$ vs $35 \%(16 / 46)$ & $0.85(0.49-1.47)$ & 0.68 \\
\hline & & 2 & $33 \%(17 / 51)$ vs $30 \%(18 / 59)$ & $1.1(0.63-1.88)$ & 0.84 \\
\hline \multirow[t]{2}{*}{ S. aureus } & & 2 & $46 \%(12 / 26)$ vs $0 \%(0 / 3)$ & $n / a$ & 0.25 \\
\hline & & 4 & $31 \%(5 / 16)$ vs $54 \%(7 / 13)$ & $0.58(0.28-1.58)$ & 0.27 \\
\hline \multirow[t]{2}{*}{ Oral Flora } & & 1 & $22 \%(13 / 60)$ vs $34 \%(23 / 67)$ & $0.63(0.35-1.13)$ & 0.12 \\
\hline & & 2 & $23 \%(9 / 39)$ vs $31 \%(27 / 88)$ & $0.75(0.39-1.44)$ & 0.52 \\
\hline
\end{tabular}

*Failure was defined as failing to achieve $90 \%$ of baseline percent predicted $\mathrm{FEV}_{1}$ at time of follow-up.

**Risk of failure to achieve outcome in those PEx achieving the log drop in bacterial counts relative to those events where a drop was not observed.

$\mathrm{ALL}=$ all $P$. aeruginos morphotypes, $\mathrm{MUC}=$ mucoid, $\mathrm{NON}=$ non-mucoid isolates, $\mathrm{OR}=$ odds ration, $\mathrm{Cl}=$ confidence intervals.

MSSA was more likely to demonstrate a significant bacteriologic response with 26/30 (81\%), 20/30 (67\%), 14/30 (46\%) experiencing at least a 2-log, 4-log or 6-log drop in MSSA, respectively at the end of therapy. Bacteriologic responses of MSSA and OF during PEx did not predict clinical success (Table 1). During fourteen PEx, new pathogens were apparent during twice-weekly samples, different from admission. These included Aspergillus (4), Stenotrophomonas maltophilia (4), Group C Streptococcus (3), and one each of MSSA, MRSA and $H$. influenzae. None of these resulted in changed antimicrobial management (with the exception of TMP/SMX for MRSA) and none manifested in chronic infection. Exacerbations associated with the emergence of new pathogens did not impact risk of PEx failure [5/42 (12\%) vs 9/108 (8\%), OR 1.41 (CI 0.5-3.98), $\mathrm{p}=0.54]$.

\section{Early bacteriologic response and correlation to end of therapy}

Change in CFU of $P$. aeruginosa EARLY into the antibacterial treatment correlated with change in load by the END of the treatment for ALL (Prob $>\mathrm{F}<0.0001, \mathrm{r}^{2}=$ 0.27 ), MUC (Prob $>F=0.0003, \mathrm{r}^{2}=0.189$ ) and NONMUC (Prob $>\mathrm{F}<0.0001, \mathrm{r}^{2}=0.30$ ) (Figure 4). EARLY changes in bacterial load did not, however, predict failure risk for any $P$. aeruginosa morphotype (not shown).

\section{Discussion}

PEx are increasingly recognized as a significant contributor to the progressive nature of CF lung disease [24]. Avoiding PEx is critical in this regard, and many CF therapies may exert their beneficial effects in manner [5,25-27]. However, despite attempts to limit their occurrence, PEx remain common. Given that some PEx are associated with worse outcomes than others, strategies to identify and optimize the management of these events are critical.

Anti-pseudomonal antibiotics are an integral component of PEx management. Independent of enhanced airway clearance, anti-pseudomonal antibacterials have been shown to improve pulmonary function in a linear capacity relative to reducing $P$. aeruginosa burden [18]. Few studies however, have tried to identify factors associated with enhanced $P$. aeruginosa killing. Smith et al., followed 75 patients chronically infected with $P$. aeruginosa through PEx managed with single or dual agent anti-pseudomonals [28]. While they observed a general reduction in sputum density of $P$. aeruginosa, reduced sputum DNA and protein levels, none of these factors correlated with absolute change in pulmonary function. Similarly, Mclaughlin et al., did not observe a correlation between burden of $P$. aeruginosa and absolute lung function recovery [29]. More recently, Deschaght et al., performed an observational study where they identified a correlation between improvement in lung function and reduction in $P$. aeruginosa density using quantitative PCR [30]. These studies, however, focused on aggregate analysis of lung function improvement and did not categorize individual events on the basis of success or failure, nor assess impact of individual morphotypes.

We sought to determine if bacteriologic killing as a measure of effectiveness of antibacterial therapies correlated with clinical outcomes in PEx. During antibacterial treatment of PEx, a progressive decline in P. aeruginosa burden was noted in approximately $60 \%$ of patients. This decline was predictable based on early changes in P. aeruginosa burden after only four days of treatment. Reduction in total $P$. aeruginosa burden, nor mucoid or nonmucoid isolates specifically did not, however, correlate with risk of failing to recover lung function. Enhanced 
Table 2 Treatment factors associated with reduced $P$. aeruginosa bacterial burden at END of PEx therapies

\begin{tabular}{|c|c|c|c|c|c|c|c|c|c|c|c|c|}
\hline \multirow[t]{3}{*}{ Factor } & \multicolumn{4}{|l|}{ ALL } & \multicolumn{4}{|l|}{ MUC } & \multicolumn{4}{|l|}{ NON } \\
\hline & Value & OR $(95 \% \mathrm{Cl})$ & Value & OR $(95 \% \mathrm{Cl})$ & Value & OR $(95 \% \mathrm{Cl})$ & Value & OR $(95 \% \mathrm{Cl})$ & Value & OR $(95 \% \mathrm{Cl})$ & Value & OR $(95 \% \mathrm{Cl})$ \\
\hline & \multicolumn{2}{|c|}{ 1-log reduction } & \multicolumn{2}{|c|}{ 2-log reduction } & \multicolumn{2}{|c|}{ 1-log reduction } & \multicolumn{2}{|c|}{ 2-log reduction } & \multicolumn{2}{|c|}{ 1-log reduction } & \multicolumn{2}{|c|}{ 2-log reduction } \\
\hline \multicolumn{13}{|l|}{ Antibiotics* } \\
\hline $\begin{array}{l}\text { FEP vs other } \\
A B x\end{array}$ & $\begin{array}{l}7 / 22 \text { vs } \\
61 / 97\end{array}$ & $\begin{array}{l}0.51(0.27-0.95) \\
p=0.009\end{array}$ & $6 / 22$ vs $49 / 97$ & $\begin{array}{l}0.54(0.26-1.08) \\
p=0.06\end{array}$ & $\begin{array}{l}13 / 20 \text { vs } \\
61 / 81\end{array}$ & $\begin{array}{l}0.86(0.61-1.22) \\
p=0.40\end{array}$ & $\begin{array}{l}7 / 20 \text { vs } \\
49 / 81\end{array}$ & $\begin{array}{l}0.57(0.31-1.00) \\
p=0.05\end{array}$ & $\begin{array}{l}9 / 21 \text { vs } \\
55 / 89\end{array}$ & $\begin{array}{l}0.69(0.41-1.16) \\
p=0.14\end{array}$ & $\begin{array}{l}6 / 21 \text { vs } \\
45 / 89\end{array}$ & $\begin{array}{l}0.56(0.28-1.14) \\
p=0.08\end{array}$ \\
\hline $\begin{array}{l}\text { CAZ vs } \\
\text { other ABx }\end{array}$ & $\begin{array}{l}36 / 56 \text { vs } \\
32 / 63\end{array}$ & $\begin{array}{l}1.27(0.93-1.73) \\
p=0.19\end{array}$ & $\begin{array}{l}29 / 56 \text { vs } \\
26 / 63\end{array}$ & $\begin{array}{l}1.25(0.85-1.85) \\
p=0.27\end{array}$ & $\begin{array}{l}36 / 49 \text { vs } \\
38 / 52\end{array}$ & $\begin{array}{l}1.00(0.8-1.27) \\
p=1.0\end{array}$ & $\begin{array}{l}32 / 49 \text { vs } \\
24 / 52\end{array}$ & $\begin{array}{l}1.41(0.99-2.02) \\
p=0.08\end{array}$ & $\begin{array}{l}34 / 50 \text { vs } \\
30 / 60\end{array}$ & $\begin{array}{l}1.36(0.99-1.86) \\
p=0.07\end{array}$ & $\begin{array}{l}27 / 50 \text { vs } \\
24 / 60\end{array}$ & $\begin{array}{l}1.35(0.90-2.01 \\
p=0.18\end{array}$ \\
\hline \multicolumn{13}{|c|}{ Treatment parameters* } \\
\hline $\begin{array}{l}<14 \text { vs } \\
\geq 14 \text { days }\end{array}$ & $\begin{array}{l}32 / 68 \text { vs } \\
29 / 52\end{array}$ & $\begin{array}{l}0.84(0.6-1.2) \\
p=0.36\end{array}$ & $\begin{array}{l}23 / 55 \text { vs } \\
38 / 65\end{array}$ & $\begin{array}{l}0.7(0.5-1.24) \\
p=0.09\end{array}$ & $\begin{array}{l}38 / 74 \text { vs } \\
13 / 28\end{array}$ & $\begin{array}{l}1.1(0.7-1.74) \\
p=0.8\end{array}$ & $\begin{array}{l}25 / 56 \text { vs } \\
26 / 46\end{array}$ & $\begin{array}{l}0.78(0.53-1.16) \\
p=0.3\end{array}$ & $\begin{array}{l}30 / 64 \text { vs } \\
28 / 46\end{array}$ & $\begin{array}{l}0.77(0.54-1.1) \\
p=0.17\end{array}$ & $\begin{array}{l}20 / 51 \text { vs } \\
38 / 59\end{array}$ & $\begin{array}{l}0.6(0.41-0.9) \\
p=0.01\end{array}$ \\
\hline
\end{tabular}

*Other antibiotics including aztreonam, meropenem, ciprofloxacin and dosing of tobramycin did not show significance and have not been included.

$\mathrm{CAZ}=$ Ceftazidime, $\mathrm{FEP}=$ Cefepime, $\mathrm{ABx}=$ antibiotics. 


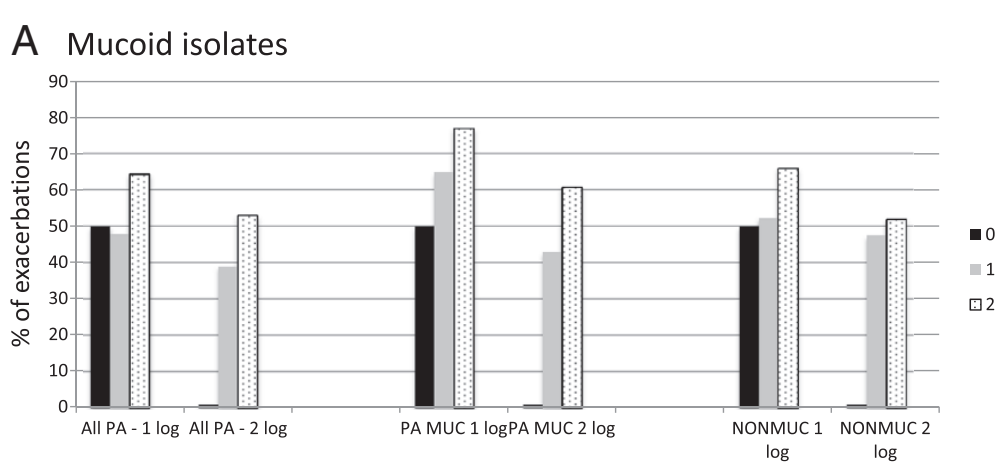

\section{B Non-mucoid}

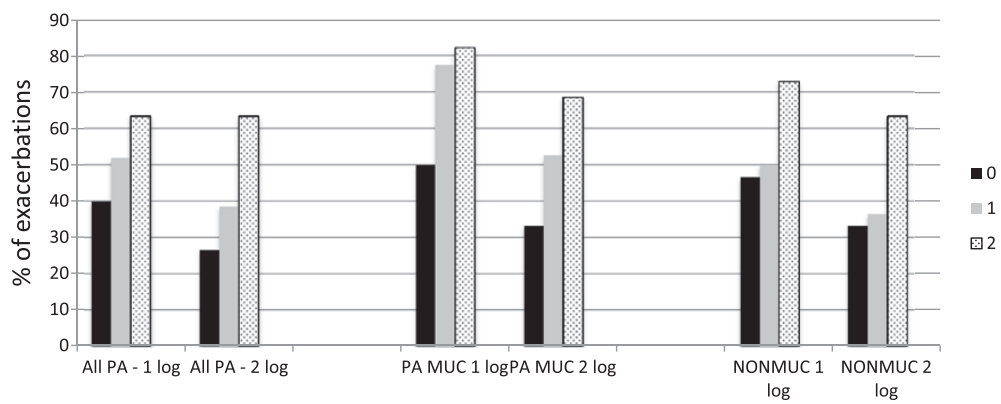

Figure 2 Percentage of PEx achieving a 1 or 2-log reduction in P. aeruginosa sputum density at end of antibacterial therapy as a function of the number of empirically provided antibiotics with in vitro predicted activity from admission sputum sample. A). Antibiotics with activity against Mucoid isolates. B). Antibiotics with activity against Non-Mucoid isolates.

killing of $P$. aeruginosa was observed in patients receiving antibacterials estimated to have more potent in vitro activity. This was particularly true when antibiotics had greater activity against non-mucoid isolates that were more readily reduced with antibiotics. Furthermore, we have observed like others, that in those few patients who transiently achieve clearance of $P$. aeruginosa during PEx treatments, no enhancement in clinical outcomes was afforded [29].

To complicate matters, studies have shown resolution of PEx in patients chronically infected with $P$. aeruginosa treated with regimens devoid of anti-pseudomonal activity suggesting response is more complicated than a one-host and one-pathogen model [31,32]. Accordingly, more recent studies have assessed the impact of antibacterials on other constituents of the CF respiratory microbiome, beyond classical CF pathogens. Using enhanced culturing to identify the Streptococcus milleri group (S. anginosus group, SMG), $40 \%$ of PEx were identified to have this organism emerge as numerically dominant at the onset of PEx, and resolution of symptoms correlated with reduction in sputum burden $[31,33,34]$. Using culture independent techniques, others have observed that with the exception of the Prevotella and Chrysiogenales, levels of

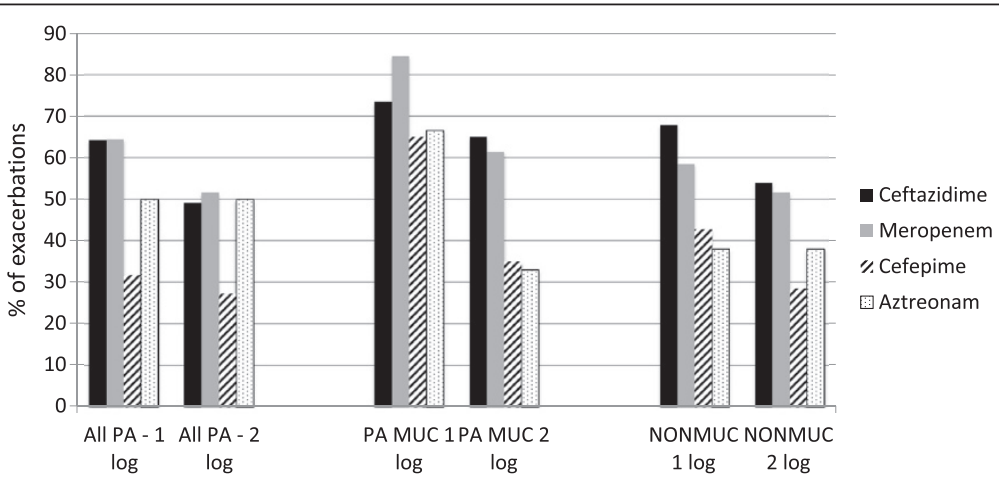

Figure 3 Percentage of PEx achieving a 1 or 2 -log reduction in P. aeruginosa sputum density at end of antibacterial therapy as a function of the $\beta$-lactam antibiotic used. 
Table 3 Relation of in vitro predicted susceptibility to reduction in P. aeruginosa bacterial burden at END of PEx therapies

\begin{tabular}{|c|c|c|c|c|c|c|c|c|c|c|c|c|}
\hline \multirow[t]{3}{*}{ Factor } & \multicolumn{4}{|l|}{ ALL } & \multicolumn{4}{|l|}{ MUC } & \multicolumn{4}{|l|}{ NON } \\
\hline & Value & OR $(95 \% \mathrm{Cl})$ & Value & OR $(95 \% \mathrm{Cl})$ & Value & OR $(95 \% \mathrm{Cl})$ & Value & OR $(95 \% \mathrm{Cl})$ & Value & OR $(95 \% \mathrm{Cl})$ & Value & OR $(95 \% \mathrm{Cl})$ \\
\hline & \multicolumn{2}{|c|}{ 1-log reduction } & \multicolumn{2}{|c|}{ 2-log reduction } & \multicolumn{2}{|c|}{ 1-log reduction } & \multicolumn{2}{|c|}{ 2-log reduction } & \multicolumn{2}{|c|}{ 1-log reduction } & \multicolumn{2}{|c|}{ 2-log reduction } \\
\hline $\begin{array}{l}\text { All Isolates S to } \\
\beta \text {-lactam vs not }\end{array}$ & $59 / 91$ vs $8 / 27$ & $\begin{array}{l}2.18(C l 1.2-3.99) \\
p=0.002\end{array}$ & $48 / 91$ vs $6 / 27$ & $\begin{array}{l}2.38(1.14-4.94) \\
p<0.01\end{array}$ & $\begin{array}{l}63 / 79 \text { vs } \\
10 / 20\end{array}$ & $\begin{array}{l}1.59(1.02-2.51) \\
p=0.01\end{array}$ & $\begin{array}{l}48 / 79 \\
\text { vs } 7 / 20\end{array}$ & $\begin{array}{l}1.73(1.0-3.23) \\
p=0.05\end{array}$ & $\begin{array}{l}55 / 81 \\
\text { vs } 8 / 27\end{array}$ & $\begin{array}{l}2.29(1.26-4.18) \\
p<0.001\end{array}$ & $\begin{array}{l}44 / 81 \\
\text { vs } 6 / 27\end{array}$ & $\begin{array}{l}2.44(1.17-5.09) \\
p=0.004\end{array}$ \\
\hline $\begin{array}{l}\text { All isolates } S \\
\text { to TOB vs not }\end{array}$ & $32 / 53$ vs $35 / 65$ & $\begin{array}{l}1.12(0.82-1.53) \\
p=0.56\end{array}$ & $29 / 55$ vs $25 / 65$ & $\begin{array}{l}1.37(0.92-2.03) \\
p=0.14\end{array}$ & $\begin{array}{l}34 / 46 \text { vs } \\
39 / 53\end{array}$ & $\begin{array}{l}1.0(0.79-1.27) \\
p=1\end{array}$ & $\begin{array}{l}28 / 46 \\
\text { vs } 27 / 53\end{array}$ & $\begin{array}{l}1.19(0.84-1.69) \\
p=0.41\end{array}$ & $\begin{array}{l}28 / 45 \\
\text { vs } 35 / 63\end{array}$ & $\begin{array}{l}1.12(0.82-1.54) \\
p=0.56\end{array}$ & $\begin{array}{l}25 / 45 \\
\text { vs } 25 / 63\end{array}$ & $\begin{array}{l}1.4(0.94-2.1) \\
p=0.12\end{array}$ \\
\hline $\begin{array}{l}\text { Regimen with } 2 \text { vs } \\
\leq 1 \text { MUC agent** }\end{array}$ & $47 / 73$ vs $12 / 25$ & $\begin{array}{l}1.34(0.87-2.08) \\
p=0.16\end{array}$ & $39 / 73$ vs $9 / 25$ & $\begin{array}{l}1.48(0.85-2.61) \\
p=0.16\end{array}$ & $\begin{array}{l}57 / 74 \text { vs } \\
16 / 25\end{array}$ & $\begin{array}{l}1.2(0.88-1.66) \\
p=0.29\end{array}$ & $\begin{array}{l}45 / 74 \\
\text { vs } 10 / 25\end{array}$ & $\begin{array}{l}1.52(0.91-2.54) \\
p=0.1\end{array}$ & N/A & & N/A & \\
\hline $\begin{array}{l}\text { Regimen with } 2 \text { vs } \\
\leq 1 \text { NON agent* }\end{array}$ & $29 / 41$ vs $33 / 67$ & $\begin{array}{l}1.43(1.05-1.96) \\
p=0.04\end{array}$ & $26 / 41$ vs $24 / 67$ & $\begin{array}{l}1.77(C l 1.19-2.63) \\
p=0.006\end{array}$ & N/A & & N/A & & $\begin{array}{l}30 / 41 \\
\text { vs } 33 / 67\end{array}$ & $\begin{array}{l}1.49(1.09-2.02) \\
p=0.02\end{array}$ & $\begin{array}{l}26 / 41 \\
\text { vs } 24 / 67\end{array}$ & $\begin{array}{l}1.77(1.19-2.63) \\
p=0.006\end{array}$ \\
\hline $\begin{array}{l}\text { MDR at PEx* } \\
\text { vs not }\end{array}$ & N/A & & N/A & & $\begin{array}{l}2 / 5 \text { vs } \\
59 / 77\end{array}$ & $\begin{array}{l}0.52(0.18-1.54) \\
p=0.1\end{array}$ & $\begin{array}{l}1 / 5 \text { vs } \\
46 / 77\end{array}$ & $\begin{array}{l}0.33(0.06-1.95) \\
p=0.15\end{array}$ & $\begin{array}{l}19 / 41 \\
\text { vs } 33 / 47\end{array}$ & $\begin{array}{l}0.66(0.45-0.96) \\
p=0.03\end{array}$ & $\begin{array}{l}14 / 41 \\
\text { vs } 27 / 47\end{array}$ & $\begin{array}{l}0.6(0.36-0.97) \\
p=0.03\end{array}$ \\
\hline $\begin{array}{l}\text { MDR in prior year* } \\
\text { vs not }\end{array}$ & $\mathrm{N} / \mathrm{A}$ & & N/A & & $\begin{array}{l}13 / 18 \text { vs } \\
47 / 63\end{array}$ & $\begin{array}{l}0.96(0.96-0.7-1.3) \\
p=1\end{array}$ & $\begin{array}{l}11 / 18 \\
\text { vs } 36 / 63\end{array}$ & $\begin{array}{l}1.06(0.7-1.63) \\
p=0.8\end{array}$ & $\begin{array}{l}22 / 51 \\
\text { vs } 30 / 36 \text {, }\end{array}$ & $\begin{array}{l}0.52(0.36-0.73) \\
p<0.001\end{array}$ & $\begin{array}{l}17 / 51 \\
\text { vs } 24 / 36\end{array}$ & $\begin{array}{l}0.5(0.32-0.78) \\
p=0.003\end{array}$ \\
\hline PDR at PEx* vs not & N/A & & N/A & & $\begin{array}{l}0 / 1 \text { vs } \\
61 / 81\end{array}$ & $\mathrm{n} / \mathrm{a} \mathrm{p}=0.21$ & $\begin{array}{l}0 / 1 \text { vs } \\
46 / 79\end{array}$ & $\mathrm{n} / \mathrm{a} \mathrm{p}=0.4$ & $\begin{array}{l}5 / 13 \\
\text { vs } 47 / 75\end{array}$ & $\begin{array}{l}0.61(0.3-1.29) \\
p=0.13\end{array}$ & $\begin{array}{l}4 / 13 \text { vs } \\
37 / 75\end{array}$ & $\begin{array}{l}0.62(0.27-1.45) \\
p=0.24\end{array}$ \\
\hline $\begin{array}{l}\text { PDR in prior year* } \\
\text { vs not }\end{array}$ & N/A & & N/A & & $\begin{array}{l}0 / 1 \text { vs } \\
59 / 79\end{array}$ & $\mathrm{n} / \mathrm{a} p=0.26$ & $\begin{array}{l}0 / 1 \text { vs } \\
46 / 79\end{array}$ & $n / a p=0.43$ & $\begin{array}{l}8 / 22 \\
\text { vs } 43 / 65\end{array}$ & $\begin{array}{l}0.55(0.31-0.98) \\
p=0.02\end{array}$ & $\begin{array}{l}7 / 22 \\
\text { vs } 34 / 65\end{array}$ & $\begin{array}{l}0.61(0.32-1.17), \\
p=0.14\end{array}$ \\
\hline
\end{tabular}

*In these events, bacteriologic response of $P$. aeruginosa was evaluated specifically against the morphotype type that susceptibility was being evaluated.

$S=$ sensitive as defined by CLSI criteria. TOB $=$ tobramycin. $M U C=$ mucoid isolate, $N O N=$ non-mucoid isolate. $P E x=$ pulmonary exacerbation. $O R=O d d s$ ratio, $C l=$ confidence interval. $N / A=$ not applicable. MDR/PDR at event $=$ Presence of an MDR/PDR isolate at admission sputum sample of the PEx being evaluated.

MDR/PDR in prior year = Presence of an MDR/PDR isolate at any time-point in the one year prior to the PEx event being evaluated. 


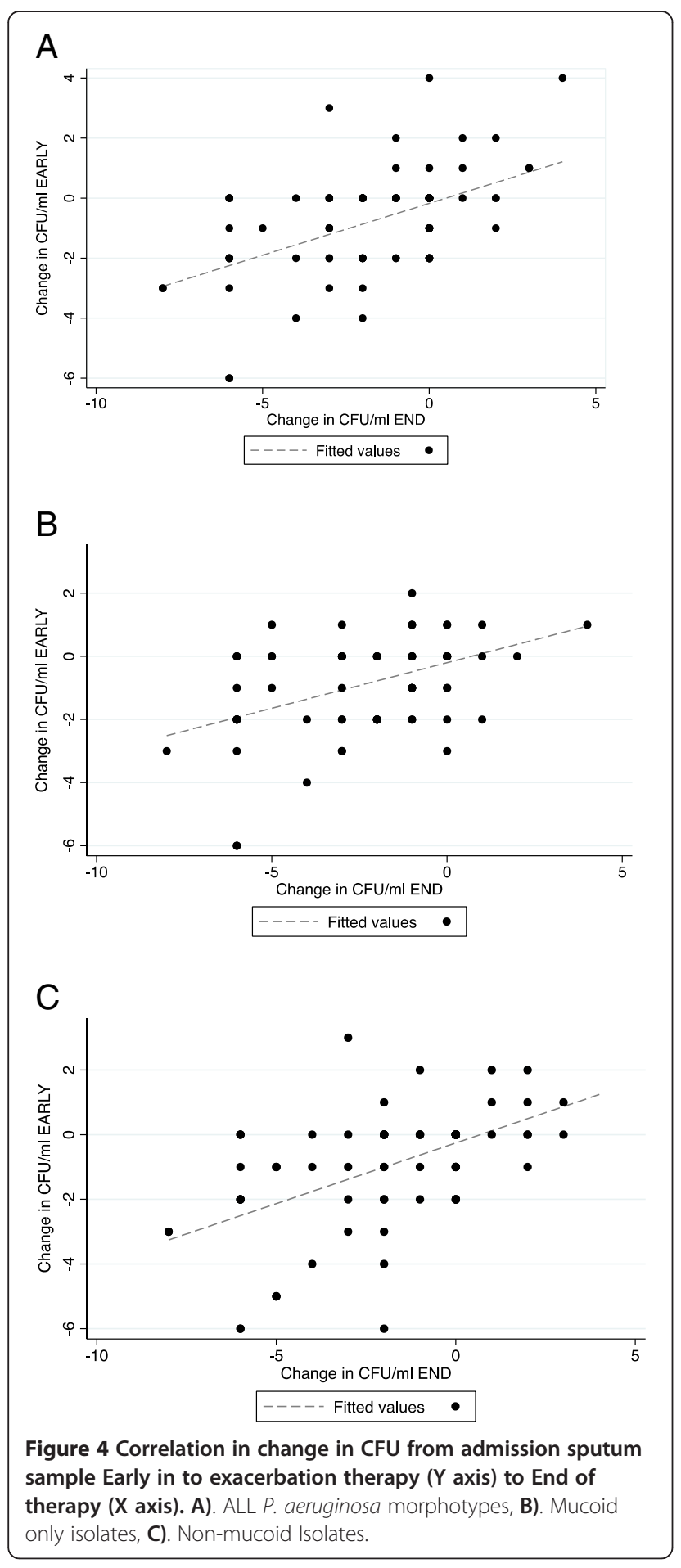

other microbiome constituents do not correlate with improvements in lung function $[35,36]$.

We did not detect an increase in either total $P$. aeruginosa load, or specifically MUC or NON morphotypes associated with an exacerbation. Nor was there an association between change in $P$. aeruginosa sputum density and extent of decline in pulmonary function. This data mirrors that of other recent studies that have challenged the long held belief that an increase in $P$. aeruginosa triggers PEx [37-39]. Clearly, factors other than changes in macroscopically apparent $P$. aeruginosa morphotypes are involved. These factors may include: environmental exposures such as pollution [40] and allergens [41]; host factors such as medication compliance [42] and co-morbidities $[15,43,44]$ pathogen factors such as respiratory viruses [45], changes in the constituents of the lower respiratory microbiome $[33,46]$ and specific $P$. aeruginosa sub-populations $[47,48]$. Furthermore, it is likely that there are multiple convergent pathways leading to a PEx, and these events vary in their manifestations and potential outcomes.

Many contentious issues exist in PEx management strategies. Data in these areas are difficult to interpret as outcomes have traditionally focused on absolute improvement in pulmonary function, as opposed to a more appropriate model of proportional recovery $[46,47]$ Whereas some, but not all studies have suggested HPTP to be inferior, we noted similar outcomes in risk of failures and reductions in $P$. aeruginosa burden [46,47]. Likewise length of therapy for PEx has been debated [49]. Herein we noted a trend towards increased risk of failure to recover lung function with therapies $\leq 10$ days, but no benefit with extending therapies $>14$ days. We also observed treatments $<14$ days were inferior in reducing $P$. aeruginosa sputum density.

The effectiveness of different antibiotics in achieving good PEx outcomes has been previously assessed. Herein we did observe differential abilities of antibiotics to reduce $P$. aeruginosa burden. In particular, cefepime was inferior at reducing $P$. aeruginosa sputum burden, although no impact on PEx outcome was noted. Interestingly, metaanalyses have demonstrated patients treated with cefepime relative to an alternate $\beta$-lactam with a similar spectrum of activity may be associated with an increased risk of mortality $[50,51]$. While commonly used in CF, the only clinical studies evaluating cefepime in CF have been pharmacokinetic based [52,53]. Based on these data, further studies of cefepime usage in CF are advisable.

ICS are common agents in CF, with approximately one third of patients receiving them. However, their utility has not clearly been established and the general consensus is that they are over used and may even be harmful [54]. Indeed, in a randomized controlled trial to evaluate the effects of discontinuation of ICS in patients stably maintained on ICS showed equivalent outcomes [55]. ICS use has been associated with increased risk of PEx $[43,56]$. Our results now suggest an increased risk of PEx failure with ICS use, a trend towards reduced sputum density of $P$. aeruginosa during antibacterial treatment and may warrant further caution with these agents in CF.

Herein we have attempted to expand upon other studies assessing PEx outcomes and changes in P. aeruginosa sputum density. To do so we have utilized a proportional lung 
function recovery model to overcome the deficiency whereby other studies using absolute improvement fail to account for the extent of initial decline and therefore are poor predictors of success or failure [15]. While this work relies on clinician diagnosed PEx events, we have retrospectively confirmed they met diagnostic criteria using an established PEx diagnostic algorithm [5]. Furthermore, we have attempted to evaluate outcomes based on individual morphotypes of $P$. aeruginosa reported routinely by clinical laboratories [20]. Indeed, quantitative analysis of $P$. aeruginosa using qPCR would not distinguish between mucoid and non-mucoid isolates. As infection with mucoid isolates of $P$. aeruginosa is associated with reduced success of eradication treatment in patients with new infection $[57,58]$ and a worse prognosis for patients with chronic lung infection [3,59], it might be expected that a differential response against mucoid isolates might impact PEx outcomes. This appears not to be the case.

Several limitations of this work deserve consideration. Because diagnosis of PEx were collected and analyzed retrospectively, the data is not as robust as prospectively collected data. Symptoms or signs not documented in clinical records may inadvertently be documented as absent. This may be somewhat mitigated, as these findings were collected at a single CF clinic over a short time period, where practice patterns were relatively uniform. Our study excluded PEx not requiring parenteral antibiotics. We observed a significantly higher rate of PEx failures than in other works $[10,11,15]$. While similar criteria were used in the selection of only parenteral antibiotic treated PEx, far fewer patients were treated with parenteral antibiotics in this study. This likely reflects institutional practice variation in the management of PEx and availability of local resources. Parenteral antibiotics were reserved for the most severe events as evidenced by the significant decline in lung function on admission. This is further supported by the relatively low level of $P$. aeruginosa drug resistance observed herein relative to other works $[15,60]$. Whether more aggressive management of exacerbations would result in improved outcomes is of interest.

\section{Conclusions}

In this work we identified that while the majority of patients treated with parenteral anti-pseudomonals experienced a temporary reduction in sputum burden, approximately $40 \%$ did not. This bacteriologic response could be predicted on the basis of sputum samples collected early into antibiotic treatment. Antibacterial treatments with a greater number of agents with in vitro predicted activity against all morphotypes, and in particular non-mucoid isolates was more likely to result in enhanced $P$. aeruginosa killing during PEx. However, patients who experienced enhanced killing of $P$. aeruginosa after completion of therapy were not afforded a reduced risk of PEx failure. Accordingly, bacteriologic response during PEx treatment cannot be used to predict success.

\section{Abbreviations}

ALL: All P. aeruginosa morphotypes; CBA: Columbia blood agar; CF: Cystic fibrosis; CFU: Colony forming unit; CHOC: Chocolate agar; Cl: Confidence intervals; CLSI: Clinical Laboratory Standards Institute; DTT: Dithiothreitol; EARLY: Sputum sample collected within $3(+/-2)$ days of treatment initiation; END: Sputum sample collected at end of therapy (within 3 days of completion); $\mathrm{FEV}_{1}$ : Forced expiratory volume in one second; HPTP: Home parenteral therapy program; ICS: Inhaled corticosteroids; IQR: Inter-quartile range; MAC: MacConkey agar; MDR: multi-drug resistant; MSSA: Methicillin sensitive Staphylococcus aureus; MRSA: Methicillin resistant Staphylococcus aureus; ml: Milliliter; MUC: Mucoid morphotypes; NON: Non-mucoid morphotypes; OF: Oropharyngeal flora; OR: Odds ratio; PDR: Pan-drug resistant; PEx: Pulmonary exacerbations; S: Sensitive; SD: Standard deviation; TMP/SMX: Trimethoprim/sulfamethoxazole; TOB: Tobramycin.

\section{Competing interests}

MDP has received research funding from Gilead sciences and participated in advisory boards for Gilead, Novartis and Roche. HRR has participated in advisory boards for Novartis and Vertex. JCL, RS and MGS report no conflicts.

\section{Author contributions}

$J C L$ was responsible for data collection, analysis and initial drafting of the manuscript. RS was responsible for data analysis, and manuscript revisions. MGS and HRR were responsible data maintenance, participated in study design and analysis, and assisted in manuscript preparation and revisions. MDP conceived the study, oversaw data collection and analysis and manuscript preparation and revisions. All authors read and approved the final manuscript.

\section{Acknowledgements}

No specific research funding was received for this project. MDP and MGS gratefully acknowledge the support of grants from Cystic Fibrosis Canada.

\section{Author details}

${ }^{1}$ Department of Medicine, The University of Calgary, 3330 Hospital Dr. NW, Calgary, Alberta T2N 4 N1, Canada. ${ }^{2}$ McMaster University, Hamilton, Ontario, Canada. ${ }^{3}$ The Department of Microbiology, Immunology and Infectious Disease, The University of Calgary, Calgary, Canada.

Received: 27 September 2014 Accepted: 20 February 2015 Published online: 22 March 2015

\section{References}

1. Razvi S, Quittell L, Sewall A, Quinton H, Marshall B, Saiman L. Respiratory Microbiology of Patients With Cystic Fibrosis in the United States, 1995-2005. Chest. 2009;136(6):1554-60.

2. Kerem E, Corey M, Stein R, Gold R, Levison H. Risk factors for Pseudomonas aeruginosa colonization in cystic fibrosis patients. Pediatr Infect Dis J. 1990;9(7):494-8.

3. Kosorok MR, Zeng L, West SE, Rock MJ, Splaingard ML, Laxova A, et al. Acceleration of lung disease in children with cystic fibrosis after Pseudomonas aeruginosa acquisition. Pediatr Pulmonol. 2001;32(4):277-87.

4. Li Z, Kosorok MR, Farrell PM, Laxova A, West SE, Green CG, et al. Longitudinal development of mucoid Pseudomonas aeruginosa infection and lung disease progression in children with cystic fibrosis. JAMA. 2005;293(5):581-8.

5. Fuchs HJ, Borowitz DS, Christiansen DH, Morris EM, Nash ML, Ramsey BW, et al. Effect of aerosolized recombinant human DNase on exacerbations of respiratory symptoms and on pulmonary function in patients with cystic fibrosis. The Pulmozyme Study Group. N Engl J Med. 1994;331(10):637-42.

6. Bilton D, Canny G, Conway S, Dumcius S, Hjelte L, Proesmans M, et al. Pulmonary exacerbation: towards a definition for use in clinical trials. Report from the EuroCareCF Working Group on outcome parameters in clinical trials. J Cyst Fibros. 2011;10(2):S79-81. 
7. Goss $\mathrm{CH}$, Burns JL. Exacerbations in cystic fibrosis. 1: Epidemiology and pathogenesis. Thorax. 2007;62(4):360-7.

8. Britto MT, Kotagal UR, Hornung RW, Atherton HD, Tsevat J, Wilmott RW. Impact of recent pulmonary exacerbations on quality of life in patients with cystic fibrosis. Chest. 2002;121(1):64-72.

9. Lieu TA, Ray GT, Farmer G, Shay GF. The cost of medical care for patients with cystic fibrosis in a health maintenance organization. Pediatrics. 1999;103(6):e72.

10. Sanders DB, Bittner RC, Rosenfeld M, Hoffman LR, Redding GJ, Goss CH. Failure to recover to baseline pulmonary function after cystic fibrosis pulmonary exacerbation. Am J Respir Crit Care Med. 2010;182(5):627-32.

11. Sanders DB, Hoffman LR, Emerson J, Gibson RL, Rosenfeld M, Redding GJ, et al. Return of FEV1 after pulmonary exacerbation in children with cystic fibrosis. Pediatr Pulmonol. 2010;45(2):127-34.

12. Mayer-Hamblett N, Rosenfeld M, Emerson J, Goss CH, Aitken ML. Developing cystic fibrosis lung transplant referral criteria using predictors of 2-year mortality. Am J Respir Crit Care Med. 2002;166(12 Pt 1):1550-5.

13. Liou TG, Adler FR, Cahill BC, FitzSimmons SC, Huang D, Hibbs JR, et al. Survival effect of lung transplantation among patients with cystic fibrosis. JAMA. 2001;286(21):2683-9.

14. McCoy KS, Quittner AL, Oermann CM, Gibson RL, Retsch-Bogart GZ, Montgomery AB. Inhaled aztreonam lysine for chronic airway Pseudomonas aeruginosa in cystic fibrosis. Am J Respir Crit Care Med. 2008;178(9):921-8.

15. Parkins MD, Rendall JC, Elborn JS. Incidence and risk factors for pulmonary exacerbation treatment failures in patients with cystic fibrosis chronically infected with Pseudomonas aeruginosa. Chest. 2012;141(2):485-93.

16. Shoki AH, Mayer-Hamblett N, Wilcox PG, Sin DD, Quon BS. Systematic review of blood biomarkers in cystic fibrosis pulmonary exacerbations. Chest. 2013;144(5):1659-70

17. Nick JA, Sanders LA, Ickes B, Briones NJ, Caceres SM, Malcolm KC, et al. Blood mRNA biomarkers for detection of treatment response in acute pulmonary exacerbations of cystic fibrosis. Thorax. 2013;68(10):929-37.

18. Regelmann WE, Elliott GR, Warwick WJ, Clawson CC. Reduction of sputum Pseudomonas aeruginosa density by antibiotics improves lung function in cystic fibrosis more than do bronchodilators and chest physiotherapy alone. Am Rev Respir Dis. 1990;141(4 Pt 1):914-21.

19. Lee TW, Brownlee KG, Conway SP, Denton M, Littlewood JM. Evaluation of a new definition for chronic Pseudomonas aeruginosa infection in cystic fibrosis patients. J Cyst Fibros. 2003;2(1):29-34.

20. Denton M. Laboratory standards for processing microbiological samples from people with cystic fibrosis. In. Edited by Trust UCF. Bromley: UK CF Trust; Sept, 2010. Available at; https://www.cysticfibrosis.org.uk/media/ 82034/CD_Laboratory_Standards_Sep_10.pdf last accessed Mar 3, 2015.

21. Parkins MD, Glezerson BA, Sibley CD, Sibley KA, Duong J, Purighalla S, et al. Twenty-five-year outbreak of Pseudomonas aeruginosa infecting individuals with cystic fibrosis: identification of the prairie epidemic strain. J Clin Microbiol. 2014;52(4):1127-35.

22. Performance Standards for Antimicrobial Susceptibility Testing; Nineteenth Informational Supplement. In. Edited by (CLSI) CaLSI, vol. M100-S19 Vol. 29 No. 3 2009: 1-156. 940 West Valley Road, Suite 1400, Wayne, Pennsylvania 19087-1898 USA

23. Hadjiliadis D, Steele MP, Chaparro C, Singer LG, Waddell TK, Hutcheon MA, et al. Survival of lung transplant patients with cystic fibrosis harboring panresistant bacteria other than Burkholderia cepacia, compared with patients harboring sensitive bacteria. J Heart Lung Transplant. 2007;26(8):834-8.

24. Waters V, Stanojevic S, Atenafu EG, Lu A, Yau Y, Tullis E, et al. Effect of pulmonary exacerbations on long-term lung function decline in cystic fibrosis. Eur Respir J. 2012:40(1):61-6.

25. Saiman L, Marshall BC, Mayer-Hamblett N, Burns JL, Quittner AL, Cibene DA, et al. Azithromycin in patients with cystic fibrosis chronically infected with Pseudomonas aeruginosa: a randomized controlled trial. JAMA. 2003;290(13):1749-56.

26. Ramsey BW, Pepe MS, Quan JM, Otto KL, Montgomery AB, Williams-Warren J, et al. Intermittent administration of inhaled tobramycin in patients with cystic fibrosis. Cystic Fibrosis Inhaled Tobramycin Study Group. N Engl J Med. 1999;340(1):23-30.

27. Assael BM, Pressler T, Bilton D, Fayon M, Fischer R, Chiron R, et al. Inhaled aztreonam lysine vs. inhaled tobramycin in cystic fibrosis: A comparative efficacy trial. J Cyst Fibros. 2013;12(2):130-40.

28. Smith AL, Redding G, Doershuk C, Goldmann D, Gore E, Hilman B, et al. Sputum changes associated with therapy for endobronchial exacerbation in cystic fibrosis. J Pediatr. 1988;112(4):547-54.
29. McLaughlin FJ, Matthews Jr WJ, Strieder DJ, Sullivan B, Taneja A, Murphy P, et al. Clinical and bacteriological responses to three antibiotic regimens for acute exacerbations of cystic fibrosis: ticarcillin-tobramycin, azlocillin-tobramycin, and azlocillin-placebo. J Infect Dis. 1983;147(3):559-67.

30. Deschaght $P$, Schelstraete $P$, Van Simaey L, Vanderkercken M, Raman A, Mahieu $L$, et al. Is the improvement of CF patients, hospitalized for pulmonary exacerbation, correlated to a decrease in bacterial load? PLoS One. 2013;8(11):e79010.

31. Parkins MD, Sibley CD, Surette MG, Rabin HR. The Streptococcus milleri group-an unrecognized cause of disease in cystic fibrosis: a case series and literature review. Pediatr Pulmonol. 2008;43(5):490-7.

32. Beaudry PH, Marks MI, McDougall D, Desmond K, Rangel R. Is anti-Pseudomonas therapy warranted in acute respiratory exacerbations in children with cystic fibrosis? J Pediatr. 1980;97(1):144-7.

33. Sibley CD, Grinwis ME, Field TR, Parkins MD, Norgaard JC, Gregson DB, et al. McKay agar enables routine quantification of the 'Streptococcus milleri' group in cystic fibrosis patients. J Med Microbiol. 2010;59(Pt 5):534-40.

34. Sibley $C D$, Parkins MD, Rabin HR, Surette MG. The relevance of the polymicrobial nature of airway infection in the acute and chronic management of patients with cystic fibrosis. Curr Opin Investig Drugs. 2009;10(8):787-94.

35. Zemanick ET, Harris JK, Wagner BD, Robertson CE, Sagel SD, Stevens MJ, et al. Inflammation and airway microbiota during cystic fibrosis pulmonary exacerbations. PLoS One. 2013;8(4):e62917.

36. Twomey KB, Alston M, An SQ, O'Connell OJ, McCarthy Y, Swarbreck D, et al. Microbiota and metabolite profiling reveal specific alterations in bacterial community structure and environment in the cystic fibrosis airway during exacerbation. PLoS One. 2013:8(12):e82432.

37. Fothergill JL, Ledson MJ, Walshaw MJ, McNamara PS, Southern KW, Winstanley C. Comparison of real time diagnostic chemistries to detect Pseudomonas aeruginosa in respiratory samples from cystic fibrosis patients. J Cyst Fibros. 2013;12(6):675-81.

38. Reid DW, Latham R, Lamont IL, Camara M, Roddam LF. Molecular analysis of changes in Pseudomonas aeruginosa load during treatment of a pulmonary exacerbation in cystic fibrosis. J Cyst Fibros. 2013;12(6):688-99.

39. Stressmann FA, Rogers GB, Marsh P, Lilley AK, Daniels TW, Carroll MP, et al. Does bacterial density in cystic fibrosis sputum increase prior to pulmonary exacerbation? J Cyst Fibros. 2011;10(5):357-65.

40. Goeminne PC, Kicinski M, Vermeulen F, Fierens F, De Boeck K, Nemery B, et al. Impact of air pollution on cystic fibrosis pulmonary exacerbations: a case-crossover analysis. Chest. 2013;143(4):946-54.

41. McCuaig S, Martin JG. How the airway smooth muscle in cystic fibrosis reacts in proinflammatory conditions: implications for airway hyper-responsiveness and asthma in cystic fibrosis. Lancet Respir Med. 2013;1 (2):137-47.

42. Briesacher BA, Quittner AL, Saiman L, Sacco P, Fouayzi H, Quittell LM. Adherence with tobramycin inhaled solution and health care utilization. BMC Pulm Med. 2011;11:5.

43. Block JK, Vandemheen $\mathrm{KL}$, Tullis E, Fergusson D, Doucette $\mathrm{S}$, Haase $\mathrm{D}$, et al. Predictors of pulmonary exacerbations in patients with cystic fibrosis infected with multi-resistant bacteria. Thorax. 2006;61(11):969-74.

44. Sequeiros IM, Jarad N. Factors associated with a shorter time until the next pulmonary exacerbation in adult patients with cystic fibrosis. Chron Respir Dis. 2012;9(1):9-16.

45. Etherington C, Naseer R, Conway SP, Whitaker P, Denton M, Peckham DG. The role of respiratory viruses in adult patients with cystic fibrosis receiving intravenous antibiotics for a pulmonary exacerbation. J Cyst Fibros. 2014;13(1):49-55.

46. Sibley CD, Parkins MD, Rabin HR, Duan K, Norgaard JC, Surette MG. A polymicrobial perspective of pulmonary infections exposes an enigmatic pathogen in cystic fibrosis patients. Proc Natl Acad Sci U S A. 2008:105(39):15070-5.

47. Workentine ML, Sibley CD, Glezerson B, Purighalla S, Norgaard-Gron JC, Parkins MD, et al. Phenotypic heterogeneity of Pseudomonas aeruginosa populations in a cystic fibrosis patient. PLoS One. 2013;8(4):e60225.

48. Mowat E, Paterson S, Fothergill JL, Wright EA, Ledson MJ, Walshaw MJ, et al. Pseudomonas aeruginosa Population Diversity and Turnover in Cystic Fibrosis Chronic Infections. Am J Respir Crit Care Med. 2011;183(12):1674-9.

49. Plummer A, Wildman M. Duration of intravenous antibiotic therapy in people with cystic fibrosis. Cochrane Database Syst Rev. 2013;5:CD006682.

50. Yahav D, Paul M, Fraser A, Sarid N, Leibovici L. Efficacy and safety of cefepime: a systematic review and meta-analysis. Lancet Infect Dis. 2007;7(5):338-48 
51. Paul M, Yahav D, Fraser A, Leibovici L. Empirical antibiotic monotherapy for febrile neutropenia: systematic review and meta-analysis of randomized controlled trials. J Antimicrob Chemother. 2006;57(2):176-89.

52. Hamelin BA, Moore N, Knupp CA, Ruel M, Vallee F, LeBel M. Cefepime pharmacokinetics in cystic fibrosis. Pharmacotherapy. 1993;13(5):465-70.

53. Huls CE, Prince RA, Seilheimer DK, Bosso JA. Pharmacokinetics of cefepime in cystic fibrosis patients. Antimicrob Agents Chemother. 1993;37(7):1414-6

54. Balfour-Lynn IM, Welch K. Inhaled corticosteroids for cystic fibrosis. Cochrane Database Syst Rev. 2012;11:CD001915.

55. Balfour-Lynn IM, Lees B, Hall P, Phillips G, Khan M, Flather M, et al. Multicenter randomized controlled trial of withdrawal of inhaled corticosteroids in cystic fibrosis. Am J Respir Crit Care Med. 2006;173(12):1356-62.

56. Ren CL, Konstan MW, Yegin A, Rasouliyan L, Trzaskoma B, Morgan WJ, et al. Multiple antibiotic-resistant Pseudomonas aeruginosa and lung function decline in patients with cystic fibrosis. J Cyst Fibros. 2012;11(4):293-9.

57. Mayer-Hamblett N, Rosenfeld M, Gibson RL, Ramsey BW, Kulasekara HD, et al. Pseudomonas aeruginosa in vitro Phenotypes Distinguish Cystic Fibrosis Infection Stages and Outcomes. Am J Respir Crit Care Med. 2014;190(3):289-97.

58. Mayer-Hamblett N, Ramsey BW, Kulasekara H, Wolter DJ, Houston L, Pope C, et al. Pseudomonas aeruginosa Phenotypes Associated with Eradication Failure in Children with Cystic Fibrosis. Clin Infect Dis. 2014;59(5):624-31.

59. Henry RL, Mellis CM, Petrovic L. Mucoid Pseudomonas aeruginosa is a marker of poor survival in cystic fibrosis. Pediatr Pulmonol. 1992;12(3):158-61.

60. Smith AL, Fiel SB, Mayer-Hamblett N, Ramsey B, Burns JL. Susceptibility testing of Pseudomonas aeruginosa isolates and clinical response to parenteral antibiotic administration: lack of association in cystic fibrosis. Chest. 2003:123(5):1495-502.

\section{Submit your next manuscript to BioMed Central and take full advantage of:}

- Convenient online submission

- Thorough peer review

- No space constraints or color figure charges

- Immediate publication on acceptance

- Inclusion in PubMed, CAS, Scopus and Google Scholar

- Research which is freely available for redistribution 